Vol. 10 (1): 19-30 (2020)

\title{
BIOETHANOL IN TURKEY
}

\author{
Fatma ÇANKA KILIÇ,"* \\ ${ }^{I}$ Department of Energy Systems Engineering, Faculty of Technology, Kocaeli University, \\ 41380 Umuttepe, Kocaeli, Turkey;
}

*Corresponding Author Fatma ÇANKA KILIÇ, e-mail: fatmacanka@ hotmail.com;

Received June 2019; Accepted July 2019; Published January 2020;

DOI: https://doi.org/10.31407/ijees10.103

\begin{abstract}
In accordance with the estimates, fossil fuels are decreasing in the world, but these fuels will continue to be dominant sources until 2040. The share of renewable energy resources in 2040 is expected to be $16.1 \%$. Similarly, it is expected that global electricity demand will increase up to $80 \%$, by $2.3 \%$ rate annually, by 2040 . In the light of all these considerations, renewable energies stand out for energy solutions all over the world. In this scope, one of the liquid biofuels, bioethanol is a good energy alternative not only for Turkey's energy future and agriculture, but also the world's as well. Sugar beet is the most convenient and efficient agricultural raw material source for bioethanol production. As the use of bioethanol production increases in Turkey, sugar beet production for bioethanol will increase, gradually. The production of biofuels from agricultural products and the energy agriculture that develops in agriculture sector is a rapidly growing in the world. Developed countries produce a significant portion of the energy in their own countries to meet their energy needs from agricultural products at an increasing rate. In this way, it is ensured that fossil fuels with limited reserves, which are known to have negative effects on the environment, will be used in less amounts and the income of the agricultural sector will be increased by producing high value-added products. In this study, one of the significant biofuels, bioethanol has been examined and its potential, technologies, importance and the latest situation in Turkey investigated. Also, it is aimed to support Turkey's one of the most important energy policies, which is to increase the production of domestic and renewable energies.
\end{abstract}

Keywords: Renewable Energy, Biomass, Biofuel, Bioethanol, Turkey 